\title{
The Influence of Diabetes Mellitus on Sodium Homeostasis in Patients with Preserved Ejection Fraction Heart Failure
}

\author{
ALEXANDRU-MADALIN BUSE ${ }^{1}$, IOAN TIBERIU NANEA ${ }^{2}$, CAMELIA NICOLAE2*, CRISTINA FLORENTINA PLESA ${ }^{3}$, \\ ROXANA MARIA NEMES ${ }^{3}$, ALINA BISOC ${ }^{4}$, MAGDALENA DIACONU5, ALINA PAUNESCU ${ }^{6}$, MONICA MARILENA TANTU 6 \\ ${ }^{1}$ The National Institute of Diabetes, Nutrition and Metabolic Diseases N.C.Paulescu, 5-7 Ion Movila Str., 020475, Bucharest, \\ Romania \\ ${ }^{2}$ Carol Davila University of Medicine and Pharmacy, 37 Dionisie Lupu Str., 020021, Bucharest, Romania \\ ${ }^{3}$ Titu Maiorescu University of Bucharest, Faculty of Medicine, 22 Dambovnicului Str., 040441, Bucharest, Romania \\ ${ }^{4}$ Transilvania University of Brasov, Faculty of Medicine, 29 Eroilor Blvd., 500036,Brasov, Romania \\ ${ }^{5}$ University of Medicine and Pharmacy Craiova, 2 Petru Rares Str., 200349, Craiova, Romania \\ ${ }^{6}$ University of Pitesti, Faculty of Sciences, Physical Education and Informatics, 1 Targu din Vale Str., 110040, Pitesti, Romania
}

The objective of the study was to analyze the characteristics of the patients with preserved ejection fraction heart failure (HfpEF) who develop hyponatremia, in relationship with the diabetes mellitus (DM). The current study is an observational retrospective one, that included 36 patients (25 women, 11 men), aged $66.6 \pm 3.1$ years, hospitalized for decompensated chronic heart failure, with a left ventricular ejection fraction $>40 \%$. $33 \%(n=12)$ of the enrolled patients had hyponatremia, which was strong associated with DM $(75 \%$ vs $17 \%$, $p<0.0005)$. In hyponatremic patients group was no association between DM and age, gendre, smoking, artrial hypertension, dyslipidemia, ejection fraction distribution orNTproBNP. As for medication at admission, we found an association of the presence of DM with betablockers ( $100 \%$ vs $67 \%, p<0.05)$ and with statins( $89 \%$ vs $67 \%, p<0.05)$. In our study, DM and non-DM patients with low serum sodium values and HfpEF have quite similar clinical profile, since the differences we found do not explain the high prevalence of DM in hyponatremic patients. As a conclusion, the presence of DM itself may explain the high prevalence of DM in hyponatremic patients, but is necessary to have larger studies with more variables included to assess HFPEF patients with DM and hyponatremia.

Keywords: Hyponatremia diabetes preserved ejection fraction

Hyponatermia (defined as serum sodium $<135 \mathrm{mmol} /$ $\mathrm{L}$ ) is a very frequent electrolyte imbalance in heart failure patients (18-30\% acording to Rusinaru et al. [1]), the percentage being similar between those who present preserved left ventricular ejection fraction and those who present reduced left ventricular ejection fraction. Hyponatremia has negative prognosis even for patients with preserved ejection fraction heart failure [1,2].

Heart failure is a cardiovascular disease with an incidence in adult population about 1-2\%, according to the last published heart failure guidelines of the European Cardiology Society in 2016 [3] and an important percentage is represented by the patients with heart failure and preserved ejection fraction. To the moment, the physiopathology of the preserved ejection fraction is not well enough known and the actual specific therapies do not improve significantly the prognosis. Moreover, the annual mortality in heart failure patients with type 2 diabetes is much higher than in those without diabetes( $36 \%$ vs 3\%, DIABHYCAR study [4]) and DM confers even a greater risk of cardiovascular death [5] or hospitalization in HfpEF patients compared to those with reduced ejection fraction [6].

The most important mechanism for hyponatremia in heart failure is dilution. Water retention occurs mainly through the non-osmotic increasing level of antidiuretic hormone, butalso through an insufficient distal tubular flow [7].The second pathophysiological mechanism for hyponatremia in heartfailure is sodium depletion, which is frequently caused by the diuretics use, by the low sodium diets, by the gastrointestinal loses or by the osmotic diuresis met in hyperglycemia $[7,8]$. It is still not completely elucidated which are the pathophysiological mechanisms of dysnatremia in patients with diabetes mellitus and heart failure, especially in those who achieve glycemic control. Until now the association between demographics, etiology and comorbidities of the patients with $\mathrm{HfpEF}$ with hyponatremia was not enough described. In this context the objective of the present study is to analyze some of the clinical and paraclinical characteristics of the in patients with preserved and mid-range ejection fraction heart failure who develop hyponatremia, in relationship with diabetes.

\section{Experimental part}

The study was created to isolate high risk patients for development of low serum sodium values. The useful parameters for this analysis may be a lot, but the current study wants to create a group of patients which develops more frequently hyponatremia, from the perspective of clinical practice and high workload from a hospital section.

The current study is an observational retrospective one, which included 36 patients hospitalized in the clinical sections Cardiology and Internal Medicine of the Clinical Hospital Prof.dr. Th. Burghele from Bucharest during the period 01.01.2016-01.06.2017. The clinical parameters considered useful for our study were: gender, age and the cardiovascular risk factors: diabetes, smoking $[9,10]$, hypertension, metabolic syndrome [11]. The laboratory parameters utilized in our analysis were plasmatic electrolytes (natremia), plasmatic values of natriuretic atrial factor. The echocardiographic parameter was left ventricle ejection fraction. 
We included patients who presented decompensated chronic heartfailure, with a left ventricular ejection fraction $>40 \%$. In May 2016 it was published the current guideline for heart failure by the European Society of Cardiology, where the old class of preserved ejection fraction heart failure $(>40 \%)$ is split in preserved ejection fraction heart failure $(>50 \%)$ and mid-range ejection fraction( $40-50 \%)$ [3]. At the begging of the study it was still valid the previous classification of Heart failure consisting only of preserved ejection fraction ( $>40 \%$ ) and reduced ejection fraction $(<40 \%)$ heartfailure. Therefore, we refer to the whole group as patients with preserved ejection fraction, but we made also a separate analyze for the patients with an ejection fraction $40-50 \%$. We determined the value of NT-proBNP to each patient, which is a specifically biological marker of heart failure.

The exclusion criteria were:

-Acute coronary syndrome, moderate/Severe valvulopathies, pericarditis, primitive or secondary, primary/secondary lesions of cardiac muscle, primaryl secondary moderate or severe arterial pulmonary hypertension; rhythm and conduction disorders

-Pulmonary thromboembolism

-Oncological [12-15], hematological or endocrinological disorder

-Infection with Clostridium Difficile or other pathogens, diabetic foot [16-18]

-Acute kidney failure/chronic kidney disease, respiratory failure [19]

-Glycosylated hemoglobin value $>6.5 \%$ or fasting plasma glucose $>110 \mathrm{mg} / \mathrm{dL}$

Clinically, it has been noticed the presence of symptoms( breathlessness, ankle swelling and fatigue), that may be accompanied by signs (e.g. elevated jugular venous pressure, pulmonary crackles and peripheral oedema) [3].

Laboratory values evaluated were: Blood count, ESR, lonogram, Fibrinogen, C-reactive Protein, Uric acid, Urea, Creatinine, Lipid profile, AST/ALT, Gamma-glutamil Transpeptidase, Troponin, CK-MB, D-dimers, NT-proBNP, Glycosylated hemoglobin, blood glucose levels.

Measuring of serum sodium was realized using an apparatus ILyte Ion Selective Electrode Analyzer.

For echocardiographic assessment was used $2 \mathrm{D}$ technique. Patients were evaluated echocardiographic using Prosound SSD 4000 SV or VIVID gBT1. The evaluated parameter was left ventricle ejection fraction using Simpson method.

Beside the already mentioned investigations, the patients where monitored radiologically and electrocardiographically. The patients were assessed clinical and paraclinical during the entire hospitalization until discharge, but the data for our study are from the admission (first 24 hours).

For additional analyses the patients were divided depending on the presence or absence of the hyponatremia. Hyponatremia was defined as a serum sodium concentration lower that $135 \mathrm{mmol} / \mathrm{L}$ according to the Clinical practice guideline on diagnosis and treatment of hyponatraemia published in European Journal of Endocrinology, 2014 [8]. According to the same guideline, patients with values $130-135 \mathrm{mmol} / \mathrm{L}$ have mild hyponatremia, with values $125-130 \mathrm{mmol} / \mathrm{L}$ have moderate hyponatremia and with values $<125 \mathrm{mmol} / \mathrm{L}$ have severe hyponatremia. Dyslipidemia diagnosis was realized utilizing the guideline of the European Society of Cardiology for management if dyslipidemia, 2016 [20].
Observing that diabetes has an increased prevalence in the hyponatremic patients group we made further analyses on hyponatremic patients, dividing them in the subgroup of patients with DM and non-DM patients. The data were collected from hospitalized patient's files, respecting ethical standards in research and personal data protection $[21,22]$.

The statistical analyses implied Student t test and correlations utilizing the coefficient $\varphi$, both realized in Microsoft Office Excel 2007. For dichotomous variables we calculated coefficient 0 . We interpreted results of coefficient $\varphi$ related to Pearson correlation table. For numerical variables we used student $t$ test. For both the calculations we considered a $p$ value $<0.05$ as significant.

\section{Results and discussions}

The analysis included 36 patients (mean age $66.6 \pm 3.1$, $69 \%$ women, $31 \%$ men) hospitalized for heart failure. $36 \%$ of patients had diabetes mellitus. The baseline characteristics and the medication at the time of the presentation of the patients enrolled are listed below (table 1, table 2).

Table 1

BASELINE CHARACTERISTICS OF THE PATIENTS ENROLLED

\begin{tabular}{|l|l|}
\hline & Patients enrolled (n=36) \\
\hline Age, years (SD) & $66.6 \pm 3.1$ \\
\hline Arterial hypertension & $97 \%(35 \mathrm{p})$ \\
\hline Dyslipidemia & $58 \%(21 \mathrm{p})$ \\
\hline Diabetes mellitus & $36 \%(13 \mathrm{p})$ \\
\hline Smoking & $36 \%(13 \mathrm{p})$ \\
\hline Women & $69 \%(25 \mathrm{p})$ \\
\hline Men & $31 \%(11 \mathrm{p})$ \\
\hline LVEF, \%(SD) & $50.83 \pm 4,4$ \\
\hline NT proBNP $<2000 \mathrm{pg} / \mathrm{mL}$ & $64 \%(23 \mathrm{p})$ \\
\hline NT proBNP $₹ 2000 \mathrm{pg} / \mathrm{mL}$ & $36 \%(13 \mathrm{p})$ \\
\hline
\end{tabular}

LVEF - left ventricle ejection fraction;

NT-proBNP - N terminal prohormone

of brain natriuretic peptide; n.s. - not significant; p - patients;

$\mathrm{SD}$ - standard deviation

Hyponatremia was met in $12(33.3 \%)$ patients, while the other $24(66.6 \%)$ had normal serum sodium levels (table 3). First, we researched association between hyponatremia and clinical characteristics of the patients enrolled. The correlation of hyponatremia with baseline characters and with medication at presentation are listed below (table 4 and 5). For the correlation with gender, comorbidities, NT-proBNP value and medication was used the calculation of $\varphi$ coefficient, for $2 \times 2$, related to $r$ Pearson coefficient table. For the correlation with LVEF value it was used student t test.

There was no association between hyponatremia and arterial hypertension, dyslipidemia, smoking or gender, but it was strong associated with diabetes mellitus ( $75 \%$ vs $17 \%, P<0.0005$ ), (table 4).

It is well known that at increased values of the glycemia, the hyponatremia could be explained by the effect of active osmole of blood glucose, resulting in a hypertone 
Table 2

MEDICATION AT ADMISSION OF THE PATIENTS ENROLLED

\begin{tabular}{|l|l|}
\hline Treatment & $\begin{array}{l}\text { Patients } \\
\text { enrolled } \\
(\mathbf{n}=36)\end{array}$ \\
\hline RAAS - ACEI & $\begin{array}{l}69 \%(25 \\
\mathrm{p})\end{array}$ \\
\hline RAAS - ARB & $25 \%(9 \mathrm{p})$ \\
\hline RAASI - Total & $89 \%(32 \mathrm{p})$ \\
\hline Beta blockers & $78 \%(29 \mathrm{p})$ \\
\hline Statins & $56 \%(20 \mathrm{p})$ \\
\hline Calcium channel blocker & $61 \%(22 \mathrm{p})$ \\
\hline Antiplatelet agents & $32 \%(11 \mathrm{p})$ \\
\hline Diuretics & $91 \%(34 \mathrm{p})$ \\
\hline Double antihypertensive association "Polipill" & $35 \%(13 \mathrm{p})$ \\
\hline Triple antihypertensive association "Polipill" & $15 \%(6 \mathrm{p})$ \\
\hline
\end{tabular}

LVEF -left ventricle ejection fraction; NT-proBNP -N terminal prohormone of brain natriuretic peptide; n.S. -not significant; p -patients; $S D$ - standard deviation. leading to the absorption of an hypotonus liquid [23]. In Rusinaru etal. study diabetes and hyponatremia in patients with preserved ejection fraction heart failure were not corelated( 29 vs $25 \%, p=0.092$ ), but they were correlated in heart failure patients regardless ejection fraction and in heart failure with reduced ejection fraction heart failure [1]. In a study with heart failure patients included regardless ejection fraction hyponatremia was correlated only with insulin use, and not with oral antidiabetic agents [24].The percentage of patients with DM in hyponatremic patients was pretty high in our study and it is necessary to mention that we had a small basis of patients which included also patients with an ejection fraction between $40-50 \%$ and there are only patients evaluated during hospitalization. Rusinaru's study included also outpatients. Nonetheless all our hyponatremic patients had either severe or moderate hyponatremia (table 3).

In our first analysis the presence of hyponatremia was associated, beside diabetes with a lower ejection fraction and with higher values of NT-proBNP, suggesting that hyponatremic patients have a more severe form of heart failure (table 4). Hyponatremia also is associated with the utilization of betablockers, double antihypertensive association, diuretics (table 5).

Observing that in hyponatremic patients the diabetes had a great prevalence we decided to further investigate

\begin{tabular}{|c|c|c|c|}
\hline \multicolumn{3}{|c|}{ HYPONATREMIA } & NORMAL SERUM SODIUM \\
\hline \multirow{3}{*}{} & $\begin{array}{c}120-124 \mathrm{mmol} / \mathrm{L} \\
125-130 \mathrm{mmol} / \mathrm{L} \\
\text { TOTAL }\end{array}$ & $\begin{array}{c}\text { 9p } \\
12 \mathrm{p}(33.3 \%)\end{array}$ & $24(66.6 \%)$ \\
& & & \\
\hline
\end{tabular}

Table 3

NATREMIA DISTRIBUTION IN THE WHOLE GROUP

Table 4

DISTRIBUTION OF THE BASELINE CHARACTERISTICS IN THE GROUP OF PATIENTS WITH NORMAL

SERUM SODIUM AND LOW SERUM SODIUM

\begin{tabular}{|c|c|c|c|}
\hline & $\begin{array}{l}\text { LOW SERUM SODIUM } \\
(\mathrm{n}=12)\end{array}$ & $\begin{array}{l}\text { NORMAL SERUM SODIUM } \\
(\mathrm{n}=24)\end{array}$ & Statistical significance \\
\hline Age $<65$ years & $41 \%(5 p)$ & $33 \%(8 p)$ & \multirow[t]{2}{*}{$P>0.05$, n.s. $(\varphi=0,12)$} \\
\hline Age $>=65$ years & $58 \%(7 p)$ & $66 \%(16 \mathrm{p})$ & \\
\hline Arterial hypertension & $100 \%(12 \mathrm{p})$ & $96 \%(23 p)$ & $P>0.05$, n.s. $(\varphi=0,12)$ \\
\hline Dyslipidemia & $67 \%(8 p)$ & $54 \%(13 p)$ & $P>0.05$, n.s. $(\varphi=0,12)$ \\
\hline Diabetes mellitus & $75 \%(9 p)$ & $17 \%(4 p)$ & ${ }^{*} \mathrm{P}<0,0005,(\varphi=0,57)$ \\
\hline Smoking & $25 \%(3 p)$ & $42 \%(10 p)$ & $P>0.05$, n.s. $(\varphi=-0.16)$ \\
\hline Women & $58 \%(7 p)$ & $75 \%(18 \mathrm{p})$ & $P>0.05$, n.s. $(\varphi=-0.17)$ \\
\hline LVEF, \% (SD) & $46.3 \pm 4.1$ & $53.1 \pm 2,4$ & ${ }^{*} \mathrm{P}<0.005,(\mathrm{t}=3,5)$ \\
\hline $\begin{array}{l}\text { NTproBNP }<2000 \\
\text { pg/mL }\end{array}$ & 0 & $95.83 \%(23 \mathrm{p})$ & \multirow[t]{2}{*}{${ }^{*} \mathrm{P}<0.0005,(\mathrm{Q}=0,941)$} \\
\hline $\begin{array}{l}\text { NTproBNP } \geq 2000 \\
\text { pg/mL }\end{array}$ & $100 \%(12 \mathrm{p})$ & $4.16 \%(1 \mathrm{p})$ & \\
\hline
\end{tabular}

${ }^{*} \mathrm{P}$ values $<0.05$ were considered significant; LVEF left ventricle ejection fraction; NTproBNP N terminal prohormone

of brain natriuretic peptide; $n$.s. - not significant; $\mathrm{p}$ (lowercase) patients; $\mathrm{P}$ (uppercase) probability value; SD-standard deviation

hyponatremia[7]. In our study the hyperglycemic patients were excluded. According to Liamis et al., it was proved an association of diabetes mellitus with hyponatremia even in the situation of glycemic levels not that high as needed to explain hyponatremia or in the absence of a predisposing associate medication (such as loop diuretics). An explanation could be the abnormal metabolism of antidiuretic hormone or the impairment of gastric motility correlations between hyponatremia and diabetes. We divided the hyponatremic patients in two subgroups, those with diabetes $(n=9)$ and those without diabetes $(n=3)$. We analyzed the main characteristics of the two subgroups (table 6), but also, the medication (table 7), and the distribution of patients based on left ventricular ejection fraction (fig. 1). For age, gender, comorbidities, medication and left ventricular ejection fraction we used coefficient $\varphi$ 
Table 5

CORRELATION BETWEEN MEDICATION AT ADMISSION AND THE PRESENCE OF HYPONATREMIA

\begin{tabular}{|c|c|c|c|}
\hline Treatment & $\begin{array}{l}\text { Low serum sodium (n } \\
=12 \text { ) }\end{array}$ & $\begin{array}{l}\text { Normal serum } \\
\text { sodium }(n=24)\end{array}$ & Statistical significance \\
\hline RAAS - ACEI & $83 \%(10 \mathrm{p})$ & $62.5 \%(15 \mathrm{p})$ & $P>0.05$, n.s. $(\varphi=0.21)$ \\
\hline RAAS - ARB & $25 \%(3 \mathrm{p})$ & $25 \%(6 \mathrm{p})$ & $\mathrm{P}>0.05$, n.s. $(\varphi=0)$ \\
\hline RAASI - Total & $100 \%(12 \mathrm{p})$ & $83 \%(20 \mathrm{p})$ & $P>0.05$, n.s. $(\varphi=0.25)$ \\
\hline Beta blockers & $92 \%(11 \mathrm{p})$ & $46 \%(13 p)$ & ${ }^{*} \mathrm{P}<0.025,(\varphi=0.38)$ \\
\hline Statins & $75 \%(9 \mathrm{p})$ & $54 \%(13 \mathrm{p})$ & $\mathrm{P}>0.05, \mathrm{n} . \mathrm{s} .(\varphi=0.2)$ \\
\hline Calcium channel blocker & $25 \%(3 \mathrm{p})$ & $38 \%(9 \mathrm{p})$ & $\mathrm{P}>0.05$, n.s. $(\varphi=-0.13)$ \\
\hline Antiplatelet agents & $75 \%(9 \mathrm{p})$ & $71 \%(17 p)$ & $\mathrm{P}>0.05$, n.s. $(\varphi=0.04)$ \\
\hline Diuretics & $100 \%(12 \mathrm{p})$ & $79 \%(19 \mathrm{p})$ & ${ }^{*} \mathrm{P}<0.05,(\varphi=0.28)$ \\
\hline $\begin{array}{l}\text { Double antihypertensive } \\
\text { association "Polipill" }\end{array}$ & $50 \%(6 \mathrm{p})$ & $21 \%(5 \mathrm{p})$ & ${ }^{*} \mathrm{P}<0,05,(\varphi=0.3)$ \\
\hline $\begin{array}{l}\text { Triple antihy- } \\
\text { pertensive } \\
\text { association "Polipill" }\end{array}$ & $16 \%(2 \mathrm{p})$ & $13 \%(3 \mathrm{p})$ & $P>0.05$, n.s. $(\varphi=0.06)$ \\
\hline
\end{tabular}

P values $<0.05$ were considered significant; $A R B$ angiotensin receptor blocker; ACEI - angiotensin-converting enzyme inhibitor, RAAS renin-angiotensin-aldosterone system.; Double antihypertensive association between diuretic and angiotensin converting enzyme inhibitor; Triple antihypertensive association between diuretic, angiotensin converting enzyme inhibitor and calcium channel blocker; n.s. - not significant; p(lowercase) patients; P(uppercase) probability value.

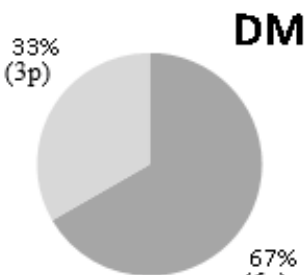

$(6 \mathrm{p})$

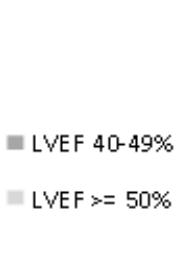

LVEF $40-49 \%$
(1)

\footnotetext{
$\mathrm{P}>0.05$, n.s. $(\varphi=0)$
}

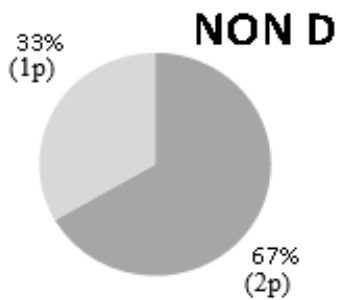

(2p)
IVEF $40-49 \%$

LVEF $>50 \%$
Fig. 1. Correlation of diabetes mellitus with the lowering of the left ventricle ejection fraction in hyponatremic patients; DM diabetes mellitus $p$ (lowercase) patients; $\mathrm{P}$ (uppercase) probability value.

\begin{tabular}{|c|c|c|c|}
\hline & DM (n=9) & NonDM(n=3) & Statistical significance \\
\hline Age $<65$ years & $33 \%(3 \mathrm{p})$ & $67 \%(2 \mathrm{p})$ & \multirow{2}{*}{$\mathrm{P}>0.05$, n.s. $(\varphi=-0.29)$} \\
\hline Age $\geq 65$ years & $67 \%(6 \mathrm{p})$ & $33 \%(1 \mathrm{p})$ & \\
\hline Arterial hypertension & $100 \%(12 \mathrm{p})$ & $100 \%(0 \mathrm{p})$ & $\mathrm{P}>0.05$, n.s. $(\varphi=0)$ \\
\hline Dyslipidemia & $67 \%(6 \mathrm{p})$ & $67 \%(2 \mathrm{p})$ & $\mathrm{P}>0.05$, n.s. $(\varphi=0)$ \\
\hline Women & $22 \%(2 \mathrm{p})$ & $33 \%(1 \mathrm{p})$ & $\mathrm{P}>0.05$, n.s. $(\varphi=0.29)$ \\
\hline Smoking & $67 \%(6 \mathrm{p})$ & $33 \%(1 \mathrm{p})$ & $\mathrm{P}>0.05$, n.s. $(\varphi=-0.11)$ \\
\hline NT-proBNP, pg/ml (SD) & $2691 \pm 271$ & $2800 \pm 219$ & $\mathrm{P}>0.1$, n.s.(t=-0,7) \\
\hline
\end{tabular}

DM diabetes mellitus; NT-proBNP N terminal prohormone of brain natriuretic peptide; n.s. not significant; p(lowercase) patients; $\mathrm{P}$ (uppercase) probability value; SD standard deviation..

correlations for $2 \times 2$, related to $\mathrm{r}$-Pearson coefficient table. For the correlation with NT-proBNP value it was used student $t$ test.

The presence of diabetes in hyponatremic patients was not associated neither with arterial hypertension, dyslipidemia, smoking, gender, age (table 6). Hypertension is usually associated with diabetes in heart failure patients $[25,26]$, but our whole group had a very high prevalence for arterial hypertension( $97 \%$ ). The other findings correspond the literature. Since all hyponatremic patients have high values of NT-proBNP, we compared the medium value between DM and non-DM patients, but there was no significant difference between diabetic and non-diabetic patients (table 6).

Regarding the association of diabetes with the medication at admission in hyponatremic patients our study shows a significant association with beta-blockers ( $100 \%$ vs $67 \% p<0.05)$ and statins ( $89 \%$ vs $67 \%, p<0.05)$ (table 7). The association with betablockers is notfound in the literature. Betablockers use seems to be associated 
Table 7

CORRELATION BETWEEN MEDICATION AT ADMISSION AND THE PRESENCE OF DIABETES IN HYPONATREMIC PATIENTS

\begin{tabular}{|c|c|c|c|}
\hline Treatment & DM & Non-DM & Statistical significance \\
\hline RAAS - ACEI & $89 \%(8 \mathrm{p})$ & $67 \%(2 \mathrm{p})$ & $\mathrm{P}>0.05$, n.s. $(\varphi=0,26)$ \\
\hline RAAS - ARB & $33 \%(3 \mathrm{p})$ & $33 \%(1 \mathrm{p})$ & $\mathrm{P}>0.05$, n.s. $(\varphi=0,00)$ \\
\hline RAASI - Total & $100 \%(9 \mathrm{p})$ & $100 \%(3 \mathrm{p})$ & $\mathrm{P}>0.05$, n.s. $(\varphi=0,00)$ \\
\hline Beta blockers & $100 \%(9 \mathrm{p})$ & $67 \%(2 \mathrm{p})$ & $* \mathrm{P}<0.05 .(\varphi=0,52)$ \\
\hline Statins & $89 \%(8 \mathrm{p})$ & $67 \%(2 \mathrm{p})$ & $* \mathrm{P}<0.05 .(\varphi=0,56)$ \\
\hline Calcium channel blocker & $22 \%(2 \mathrm{p})$ & $33 \%(1 \mathrm{p})$ & $\mathrm{P}>0.05$, n.s. $(\varphi=-0,11)$ \\
\hline Antiplatelet agents & $67 \%(6 \mathrm{p})$ & $100 \%(3 \mathrm{p})$ & $\mathrm{P}>0.05, \mathrm{n} . \mathrm{s} .(\varphi=-0,33)$ \\
\hline Diuretics & $100 \%(9 \mathrm{p})$ & $100 \%(3 \mathrm{p})$ & $\mathrm{P}>0.05$, n.s. $(\varphi=0,00)$ \\
\hline Double antihypertensive association & $56 \%(5 \mathrm{p})$ & $33 \%(1 \mathrm{p})$ & $\mathrm{P}>0.05, \mathrm{n} . \mathrm{s} .(\varphi=0,19)$ \\
\hline Triple antihypertensive association & $11 \%(1 \mathrm{p})$ & $0 \%(0 \mathrm{p})$ & $\mathrm{P}>0.05$, n.s. $(\varphi=0,17)$ \\
\hline "Polipill" & & & \\
\hline
\end{tabular}

$* \mathrm{P}$ values $<0.05$ were considered significant; $\mathrm{ARB}$ angiotensin receptor blocker; $\mathrm{ACEI}$ angiotensin-converting enzyme inhibitor; RAAS renin-angiotensin-aldosterone system; DM diabetes mellitus; Double antihypertensive association between diuretic and angiotensin converting enzyme inhibitor, Triple antihypertensive association between diuretic, angiotensin converting enzyme inhibitor and calcium channel blocker, n.s. - not significant $\mathrm{p}$ (lowercase) patients; $\mathrm{P}$ (uppercase) probability value.

with diabetes in heart failure patients selected regardless ejection fraction [26], butnotwith $\operatorname{HfpEF}[25,28]$. However betablocker use seems not to be associated with hyponatremia in $\mathrm{HFpEF}$, nor in reduced ejection fraction heart failure [1], although in our first analysis we found a significant correlation between betablockers and hyponatremia (table 5). The association of statins with diabetes was an expected one, thinking that the presence of diabetes is a criterion for initiating statins. The studies on HfpEF show an association between statins and diabetes [25,28], but statins were not associated with hyponatremia in none of the studies on $\mathrm{HfpEF}[1]$.

We analyzed the distribution of hyponatremic patients based on ejection fraction and we observed that there was no difference in the distribution of diabetic and non-diabetic patients in the group of mid-range (40-50\%) and preserved ejection fraction (>50\%) (fig. 1). In literature diabetes was not associated with change in left ventricular ejection fraction in HFpEF [25].

Regarding the medication we analyzed only the type of medication used, but a great importance may have also the dosage, especially for diuretics[26]. Another consideration is that although we excluded chronic kidney disease from our study, it would be useful in further studies to analyze the glomerular filtration rate, since the alteration of tubular function in early phases of renal diabetic impairment may contribute to electrolyte imbalance[29]. Nonetheless, we do not include anti-diabetic medication in our analysis. However the antidiabetic medication is not known as a cause for low serum sodium level, excepting first generation of sulphonylureas [23].

\section{Conclusions}

In the present study, the statistically significant differences between diabetic and non-diabetic patients with preserved ejection fraction heartfailure who develop hyponatremia do not explain the more frequent appearance of hyponatremia in diabetic patients. Since the profiles of diabetics and non-diabetics patients are quite similar, it is possible that the presence of diabetes itself and of the impairment of renal functions of secretion and absorption in diabetes, may explain the more frequent low sodium values in the subgroup of diabetes patients. It is necessary to have larger studies with more variables included to assess the patients with diabetes mellitus and low serum sodium concentration, since hyponatremia is an important risk factor for the long-term outcome in heart failure patients.

\section{Abbreviations}

AST aspartate transaminase

ALT alanine aminotransferase

CK-MBcreatine kinase

DM- diabetes mellitus

HFpEf -heart failure with preserved ejection fraction

NT-proBNP - N terminal prohormone of brain natriuretic peptide

\section{References}

1.RUSINARU, D., TRIBOUILLOY, C., BERRY, C. et al., Eur. J. Heart Fail., 14, nr. 10, 2012, p. 1139.

2.BAVISHI, C., ATHER, S., BAMBHROLIYA, A. et al., Am. J. Cardiol., 113, nr. 11, 2014, p. 1834.

3.PONIKOWSKI, P., VOORS, A. A., ANKER, S. D., et al., Eur. Heart] ., 37, nr. 27, 2016.

4.VAUR, L., GUERET, P., LIEVRE, M., CHABAUD, S., PASSA, P., Diabetes Care, 26, nr. 3, 2003, p. 855.

5.PLESA CF, NICOLAE C, SIRBU CA, NEMES R, PAUNESCU A, TANTU MM, FARMACIA, No. 67, 2019, P. 27-33

6.MACDONALD, M. R., PETRIE, M. C., VARYANI, F. et al., Eur. Heart J., 29, nr. 11, 2008, p. 1377.

7.VerbRugGe, F. H., SteELS, P., GRIETEN, L. et al., J. Am. Coll. Cardiol., 65, nr. 5, 2015.

8.SPASOVSKI, G., VANHOLDER, R., ALLOLIO, B. et al., Eur. J. Endocrinol., 170, nr. 3, 2014. 
9.POSTOLACHE, P., NEMES, RM., PETRESCU, O., etal. Medical-surgical Journal, no. 119, 2015, p. 77-80.

10.NEMES, RM., POSTOLACHE, P., TINTILA, A., etal. Medical - Surgical Journal, no. 119, 2015, p. 23-30

11.NITESCU, M., FURTUNESCU, FL., OTELEA, M., etal. Revista Romana de Medicina de Laborator, no. 20, 2012, p. 21-28.

12.STEFANESCU, D.C., CEACHIR, O., ZAINEA, V., HAINAROSIE, M., PIETROSANU, C., IONITA, I.G., HAINAROSIE, R., Rev.Chim. (Bucharest), 67,no.7, 2016, p. 1327-1328

13.STEFANESCU, D.C., CEACHIR, O., ZAINEA, V., HAINAROSIE, M., PIETROSANU,C., IONITA, I.G., HAINAROSIE, R., Rev.Chim. (Bucharest), 67,no. 7, 2016, p. 1255-1256

14.BISOC A, RADOI M, PASCU AM., Acta Endocrinologica, 2015;11(1):16.

15.BISOC, A., CIURESCU, D., RADOI, M., TANTU, MM., ROGOZEA, L., SWEIDAN, AJ., BOTA, DA., American journal of therapeutics. DOI:10.1097/MJT.0000000000000930

16.TANTU,M.M., MAN, G.M., PAUNESCU, A. et al., Rev.Chim. (Bucharest), 69, No.11, 2018, P.3001-3005

17.TANTU, M.M., MAN, G.M., ROGOZEA, L.M. et al., Rom J MorphoL EMBRYOL 2018, 59(3): 895-902

18.DUCEAC, L.D., TARCA, E., CIUHODARU, M.I., TANTU, M.M., et al.,Rev. Chim. (Bucharest), 70, no. 1, 2019, p. 199-201
19.NITU, FM., OLTEANU, M., STREBA CT., Romanian J OURnal OF Morphology And EMBRYOLOGY, No. 58, 2017, P 385-392.

20.CATAPANO, A. L., GRAHAM, I., DE BACKER, G., et al., Eur. Heart J., 37, nr. 39, 2016, p. 2999.

21.POPESCU, I.G., SECHEL, G., LEASU, F.G., et al., Rom J Morphol Embryol 2018, 59(3): 1001-1005

22.CONSTANTIN, D.A., CIORICEANU, I.H., TANTU, M.M., et al., Rom J Morphol Embryol 2017, 58(3):1121-1125

23.LIAMIS, G., LIBEROPOULOS, E., BARKAS, F., ELISAF, M., World J. Clin. cases, 2, nr. 10, 2014, p. 488.

24.GHEORGHIADE, M., ABRAHAM, W. T., ALBERT, N. M. et al., Eur. Heart J., 28, nr. 8, 2007, p. 980.

25.LINDMAN, B. R., DÁVILA-ROMAN, V. G., MANN, D. L. et al., J. Am. Coll. Cardiol., 64, nr. 6, 2014, p. 541.

26.DIACONU, C.C., STANESCU, A.M.A., PANTEA STOIAN, A., et al., Rev. Chim. (Bucharest), 69, no.6,2018,p.1367-1370.

27.ITZHAKI BEN ZADOK, O., KORNOWSKI, R., GOLDENBERG, I. et al., Cardiovasc. Diabetol., 16, nr. 1, 2017, p. 102.

28.SANDESARA, P. B., O'NEAL, W. T., KELLI, H. M. et al., Diabetes Care, 41, nr. 1, 2018, p. 150.

29.PANTEA-STOIAN, A., PITURU, S. M., HAINAROSIE, R..et al.,FARMACIA,66,nr.1,2018, p.1-7.

Manuscript received: 15.11 .2018 